\title{
Effect of the season on some aspects of the estrous cycle in Martina Franca donkey
}

\author{
A. Contri ${ }^{\text {a }}$, D. Robbe ${ }^{a}$, A. Gloria ${ }^{a, *}$, I. De Amicis ${ }^{\text {a }}$, M.C. Veronesi ${ }^{\text {b }}$, \\ A. Carluccio ${ }^{\mathrm{a}}$ \\ ${ }^{\text {a }}$ Department of Veterinary Clinical Sciences, Faculty of Veterinary Medicine, University of Teramo, Teramo, Italy \\ ${ }^{\mathrm{b}}$ Department of Health, Animal Science and Food Safety, Faculty of Veterinary Medicine, Università degli Studi di Milano, Milan, Italy
}

\section{A R T I C L E I N F O}

\section{Article history:}

Received 12 June 2013

Received in revised form 9 December 2013

Accepted 10 December 2013

\section{Keywords:}

Donkey

Estrous cycle

Estrous behavior

Follicular dynamic

Ovulation

\begin{abstract}
A B S T R A C T
The Martina Franca (MF) donkey breed, with 48 jackasses and 515 jennies, is considered an endangered breed according to the data from the Monitoring Institute for Rare Breeds and Seeds in Europe. The knowledge of the estrous cycle characteristics has a great impact for assisted reproduction, especially in endangered species. In this study, the estrous cycle characteristics were investigated in $12 \mathrm{MF}$ jennies throughout the year. Estrous cycle, estrous and diestrous lengths, follicular growth and ovulation, and estradiol-17 $\beta$ (E2) and progesterone ( $\mathrm{P} 4)$ plasma concentrations were monitored in MF jennies and compared in different seasons. In all jennies (100\%) estrous cycle was detected during the whole year, with no differences in the estrous cycle length among seasons. However, a significant increase of estrous length in spring and summer compared with autumn and winter was found. Diestrus was shorter in summer than in the other seasons. Estrous behavior was always shown and characterized by rhythmic eversion of the vulvar labia (winking) with exhibition of the clitoris, urination, male receptivity and clapping, with sialorrhoea, neck and head extension, and back ears. Estrus was characterized by the ovulation of a larger follicle in spring and summer than in autumn and winter. The pattern of E2 and P4 plasma concentrations during the estrous cycle were similar to that reported for the mare, but without differences among the four seasons, so that a negligible effect of environmental conditions on ovarian E2 and P4 secretion was hypothesized, despite the larger diameter of the ovulating follicle in spring and summer.
\end{abstract}

(c) 2014 Elsevier Inc. All rights reserved.

\section{Introduction}

In the last years, a growing importance in donkey (Equus africanus asinus) medicine has been observed as the result of the interest for hypoallergenic milk production and onotherapy. Furthermore, several donkey breeds are considered as endangered because of their small population size and serious risks of consanguinity [1]. To increase donkeys' population and breed's biodiversity preservation, several research projects on donkey reproduction have

\footnotetext{
* Corresponding author. Tel./fax: +390861 266975.

E-mail address: gloriaalessia@libero.it (A. Gloria).
}

been performed, and the knowledge on reproductive aspects of this species and breed-specific characteristics arose [2-7]. The Martina Franca (MF) breed consists of about 48 approved-for-breeding jackasses and 515 jennies, and it is therefore considered an endangered breed according to the data from the Monitoring Institute for Rare Breeds and Seeds in Europe. For these reasons, several studies addressed to the reproductive characteristics of MF jennies and jackasses [6,8-12].

The knowledge of the estrous cycle has a great impact on reproduction management because of the possible control of ovulation or diestrus, and the simple transposition of knowledge obtained in the horse to the donkey is often ineffective $[13,14]$. 
In the donkey, in example, the reproductive activity seems to be less affected by the season in comparison with the horse. Henry, et al. [15] reported that only $40 \%$ of the monitored jennies showed a seasonal anestrus, and a limited effect of the season was recently reported in the jackass $[6,16]$. In the jenny, also the estrous cycle seems to be different in comparison with the horse. The diestrus seems, in fact, to be longer in the jenny than in the mare, whereas the estrus results were of comparable length [15,17-19].

However, the possible role of the environmental conditions (temperature and natural lighting) on estrous cycle length and reproductive endocrinology of the jenny and in seasonal anestrus onset, is still not completely investigated.

In the purpose to provide new knowledge for the optimization of breeding management in the endangered MF donkey breed, the aim of this study was the evaluation of the possible seasonal effect on some reproductive aspects in the MF jenny.

\section{Materials and methods}

\subsection{Animals and location}

The study was conducted in the province of Teramo (Italy), latitude of $42^{\circ} 43^{\prime} 34.351^{\prime \prime} \mathrm{N}$ and longitude of $13^{\circ} 46^{\prime} 21.539^{\prime \prime} \mathrm{E}$, at around $270 \mathrm{~m}$ on sea levels, from January, 2008 to January, 2009. The study involved 12 healthy MF jennies, 4- to 8-year old and weighing 396 to $420 \mathrm{~kg}$. Jennies recruited for this study showed regular cycles and foaled without obstetric assistance in the previous parturition, occurred at least 60 days before the start of the study. The jennies were kept in open paddocks and subjected to the natural atmospheric conditions for the whole trial. Daily, jennies received standard hay ad libitum and commercial equine fodder $(2 \mathrm{~kg})$. The body condition score of all the jennies was between $3 / 5$ to $4 / 5$ and remained constant throughout the trial.

Calendar-based seasons were considered: winter (22 December-20 March), spring (21 March-20 June), summer (21 June-22 September), and autumn (23 September-21 December). The environmental conditions such as the amount of light hours (LH), the light ratio, as the percentage of the light hours in 24 hours (LHR), and the lower, the higher, and the mean environmental temperature (LET, HET, and MET respectively), were recorded.

\subsection{Estrus detection and ultrasonography}

Each jenny was teased daily from Day 15 after the previous ovulation with a fertile and mature jackass for at least 3 to 4 minutes [20] to verify the presence of behavioral signs of estrus. The day of the behavioral willingness to mating (heat) was considered the Day 1 of the estrus (Ed1). The day when the jenny refused the jackass was considered the Day 1 of the diestrus (Dd1). Thus, the estrus time was defined as the time, in days, between Ed1 to Dd1-1; the diestrus time was defined as the days between Dd1 to the subsequent Ed1-1. At Ed1, the behavioral characteristics of the heat were recorded and the jennies in estrus were submitted to gynecological and ultrasonographic examination. The ultrasound examinations of the reproductive tract were performed transrectally using an ultrasound Concept 2000 (Dynamic Imaging Limited, Livingston, Scotland, UK) equipped with a 7.5-MHz linear transducer. Uterus was monitored for the diameter of both horns at Ed1. Jennies with anechoic content of the uterus were excluded from the trial. The follicular dynamics was followed by ultrasonographic examinations repeated every 12 hours between Ed1 and the visualization of a follicle of 30 -mm diameter, then every 6 hours until ovulation. The day at which the dominant follicle disappeared on the ovary was defined as the day of ovulation, and the diameter of the dominant follicle at the last examination before ovulation was recorded. Estrous cycle was considered as the time elapsing between two consecutive ovulations, detected using ultrasonography.

Blood samples were daily collected from Ed1 until Ed1 of the following estrus in each jenny by venipuncture in heparinized tubes, centrifuged at $1000 \times \mathrm{g}$ for 20 minutes and plasma stored at $-20{ }^{\circ} \mathrm{C}$ until E2 and P4 analysis. This complete monitoring protocol was used for each animal and repeated during the four year-round seasons.

\subsection{Hormone assays}

Plasma E2 concentration was assayed using radioimmunoassay (RIA). The intra- and interassay coefficients of variation were $4.8 \%$ and $7.6 \%$, with a sensitivity of $1.1 \mathrm{pg}$ per tube. Plasma P4 concentration was measured using radioimmunoassay, with an intra- and interassay coefficients of variation of $4.6 \%$ and $6.9 \%$, respectively and a sensitivity of $2.3 \mathrm{pg}$ per tube. Both the methods were previously validated [21].

\subsection{Statistical analysis}

The normal distribution of data, reported as mean and standard deviation, about the estrous cycle and estrous and diestrous lengths were tested by the Kolmogorov-Smirnov test. No deviation from normality was detected.

For the hormonal analysis, the day of blood collection was normalized for ovulation (Day 0): preovulatory days considered from Day 6 to 1 and postovulatory days from Day 1 to 18. Length of estrous cycle, estrus, and diestrus were analyzed using a two-way ANOVA, in which the season and the cycle within each season were used as factors. The follicle size at Day 5 and at ovulation was analyzed using a one-way ANOVA, in which the season was considered the factor. The plasma concentrations of E2 and P4 were analyzed using a two-way ANOVA, in which the season and the day (pre- or postovulation) were considered as factors. In all cases, the post hoc evaluation was performed using the Scheffè's test. The differences were considered significant with P-value less than 0.05. All data were analyzed using the software PASW (SPSS) version 18 for Windows platform.

\section{Results}

The number of light hours/day was higher in spring and summer compared with autumn and winter $(\mathrm{P}<0.05)$, such as the percentage of light hours in the day $(P<0.05)$. 
All the temperature parameters were different in different seasons (Table 1 ).

In the present study a total of 120 estrous cycles from 12 jennies were considered. The estrous cycles examined were 32 in spring, 32 in summer, 29 in autumn, and 27 in winter.

Before ovulation, the heat behavior of the jennies in the presence of the jackass was characterized by rhythmic eversion of the vulvar labia (winking) with exhibition of the clitoris, urination, male receptivity, and clapping, with sialorrhoea, neck and head extension, and back ears. These behavioral signs lasted, during the whole year, from $5.66 \pm$ 0.51 to $7.8 \pm 0.44$ days.

The duration of estrus cycle, estrus, and diestrus were summarized in Table 2. The mean estrous cycle in the MF jennies consisted of $23.3 \pm 0.8$ days during the whole year, with similar values throughout different seasons.

On average, the estrous length was $6.5 \pm 0.6$ days and it was significantly longer $(P<0.01)$ in summer $(7.1 \pm 0.4$ days) compared with autumn (6.2 \pm 0.6 days) and winter $(6.1 \pm 0.4$ days). Estrus in spring was significantly longer than in winter $(\mathrm{P}<0.01)$.

The mean duration of the diestrus during the whole year in MF jennies was $16.8 \pm 0.6$ days. A significant reduction in diestrous length $(P<0.01)$ was reported in the summer compared with the other seasons. The diestrous was not significantly different among the other seasons.

In the MF jenny, the follicle size measured in the last examination close to ovulation was on average $43.7 \pm 0.13$ $\mathrm{mm}$, and was fluctuant, with a decreased turgidity of the wall, and a modest amount of hyperechoic particles fluctuating within the follicular fluid. The follicular diameters at Day 5 and at ovulation (Day 0) in the different seasons were reported in Table 3. The ovulation occurred 0.68 to 0.73 days before the end of the estrous behavior.

Plasma E2 concentrations showed a progressive increase from Day 6 to 2, the days of hormone peak in spring and autumn. In summer and winter, the peak seemed slightly delayed and detected on Day 1 . Then, a progressive and significant $(P<0.05)$ reduction was found between Day 2 to 1 and from Day 1 to 0 . After Day 1 in autumn, Day 2 in spring, summer, and winter, E2 basal levels were found and remained unchanged until the beginning of the subsequent heat (Fig. 1). Plasma P4 concentration was at basal level during the estrus, with no significant differences between Day 6 to 0 . Afterwards, it increased significantly $(\mathrm{P}<$ 0.01 ) from Day 1 to 3, and showed a plateau between Day 6 to 11 (spring, summer, and autumn) or Day 12 (winter).

Table 1

Environmental characteristics during the different seasons of the trial.

\begin{tabular}{lrlll}
\hline $\begin{array}{l}\text { Environmental } \\
\text { characteristic }\end{array}$ & Winter & Spring & Summer & Autumn \\
\hline LH $(\mathrm{h})$ & $10.1 \pm 0.7^{\mathrm{a}}$ & $13.9 \pm 1.3^{\mathrm{b}}$ & $13.1 \pm 1.2^{\mathrm{b}}$ & $10.3 \pm 0.8^{\mathrm{a}}$ \\
LHR $(\%)$ & $41.8 \pm 3.3^{\mathrm{a}}$ & $58.2 \pm 3.9^{\mathrm{b}}$ & $57.1 \pm 5.3^{\mathrm{b}}$ & $42.6 \pm 3.4^{\mathrm{a}}$ \\
HET $\left({ }^{\circ} \mathrm{C}\right)$ & $8.2 \pm 5.1^{\mathrm{a}}$ & $21.6 \pm 3.9^{\mathrm{b}}$ & $27.8 \pm 4.3^{\mathrm{c}}$ & $13.6 \pm 5.1^{\mathrm{d}}$ \\
LET $\left({ }^{\circ} \mathrm{C}\right)$ & $1.5 \pm 2.4^{\mathrm{a}}$ & $12.9 \pm 3.9^{\mathrm{b}}$ & $18.4 \pm 3.8^{\mathrm{c}}$ & $6.2 \pm 4.1^{\mathrm{d}}$ \\
MET $\left({ }^{\circ} \mathrm{C}\right)$ & $3.8 \pm 2.9^{\mathrm{a}}$ & $17.3 \pm 4.1^{\mathrm{b}}$ & $22.7 \pm 3.6^{\mathrm{c}}$ & $9.8 \pm 4.3^{\mathrm{d}}$ \\
\hline
\end{tabular}

a,b,c,d Different superscript alphabets in the same row mean significant differences $(\mathrm{P}<0.05)$.

Abbreviations: HET, the higher day-temperature; LET, the lower daytemperature; LH, number of light hours; LHR, percentage of the light hours in 24 hours; MET, the mean daily temperature.
Table 2

Mean \pm SD of the estrous cycle, estrous, and diestrous lengths in different seasons in 12 Martina Franca jennies.

\begin{tabular}{|c|c|c|c|}
\hline \multirow[t]{2}{*}{ Season } & Estrous cycle (days) & Estrous (days) & Diestrous (days) \\
\hline & Mean \pm SD & Mean \pm SD & Mean \pm SD \\
\hline Spring & $23.6 \pm 0.7$ & $6.7 \pm 0.4^{\mathrm{a}, \mathrm{b}}$ & $16.9 \pm 0.5^{\mathrm{a}}$ \\
\hline Summer & $23.4 \pm 0.7$ & $7.1 \pm 0.4^{\mathrm{a}}$ & $16.1 \pm 0.6^{\mathrm{b}}$ \\
\hline Autumn & $23.1 \pm 0.9$ & $6.2 \pm 0.6^{\mathrm{b}, \mathrm{c}}$ & $17.1 \pm 0.6^{\mathrm{a}}$ \\
\hline Winter & $23.1 \pm 0.7$ & $6.1 \pm 0.4^{\mathrm{c}}$ & $17 \pm 0.3^{\mathrm{a}}$ \\
\hline
\end{tabular}

a,b,c In the same column, values with different letters in superscript differ significantly $(\mathrm{P}<0.05)$.

Abbreviation: SD, standard deviation.

After this plateau, the plasma level of the hormone decreased progressively (Day 13-17) returning to basal levels (Fig. 1).

\section{Discussion}

In this study, 12 jennies were evaluated for the estrous characteristics in a whole year-round time of observation. All jennies (100\%) showed estrous cycles along the whole year; heats were observed also in winter, and always coupled to ovulation. This percentage was greater than data reported in literature, even if the presence of a year-round cyclicity was previously reported [18,22]. Henry, et al. [15] observed a seasonal anestrus in about $40 \%$ of the jennies monitored. Thus, opposite to the mare, the whole yearround reproductive activity detectable in jennies could suggest a different seasonal effect on the hypothalamicpituitary-gonadal axis in donkeys. In the mare, in the northern hemisphere, two transitional phases and a winter anestrus are reported and characterized by a partial or complete stop of reproductive activity because of a partial or complete stop of the hypothalamus-pituitary-gonadal axis [23]. This reproductive "seasonality" in the mare seems to be driven by the progressive decrease of the daylight in winter via a pineal-melatonin mechanism [24,25]. The lack of a seasonal anestrus in all MF jennies suggested a reduced effect of the seasonality on reproductive characteristics, as previously demonstrated in the MF jackass $[6,16]$.

In the present study, the mean ( $23.3 \pm 0.8$ days $)$ estrous cycle length was similar in the different seasons, in accordance with the data reported by Blanchard, et al. [22] and Meira, et al. [19]. The mean estrous and diestrous lengths (6.5 \pm 0.6 and $16.8 \pm 0.6$ days, respectively) were

Table 3

Mean \pm SD diameter of the dominant follicle at Day 5 before and at ovulation in different seasons in 12 Martina Franca jennies.

\begin{tabular}{|c|c|c|}
\hline \multirow[t]{2}{*}{ Season } & $\begin{array}{l}\text { Dominant follicle size } \\
\text { on Day }-5(\mathrm{~mm})\end{array}$ & $\begin{array}{l}\text { Dominant follicle at } \\
\text { ovulation }(\mathrm{mm})\end{array}$ \\
\hline & Mean \pm SD & Mean \pm SD \\
\hline Spring & $31.5 \pm 0.18$ & $45 \pm 0.23^{\mathrm{a}}$ \\
\hline Summer & $30.6 \pm 0.04$ & $44.2 \pm 0.32^{\mathrm{a}}$ \\
\hline Autumn & $32.8 \pm 0.02$ & $41 \pm 0.54^{\mathrm{b}}$ \\
\hline Winter & $32.4 \pm 0.12$ & $42 \pm 0.49^{b}$ \\
\hline
\end{tabular}

a,b In the same column, values with different letters in superscript differ significantly $(\mathrm{P}<0.05)$.

Abbreviation: SD, standard deviation. 

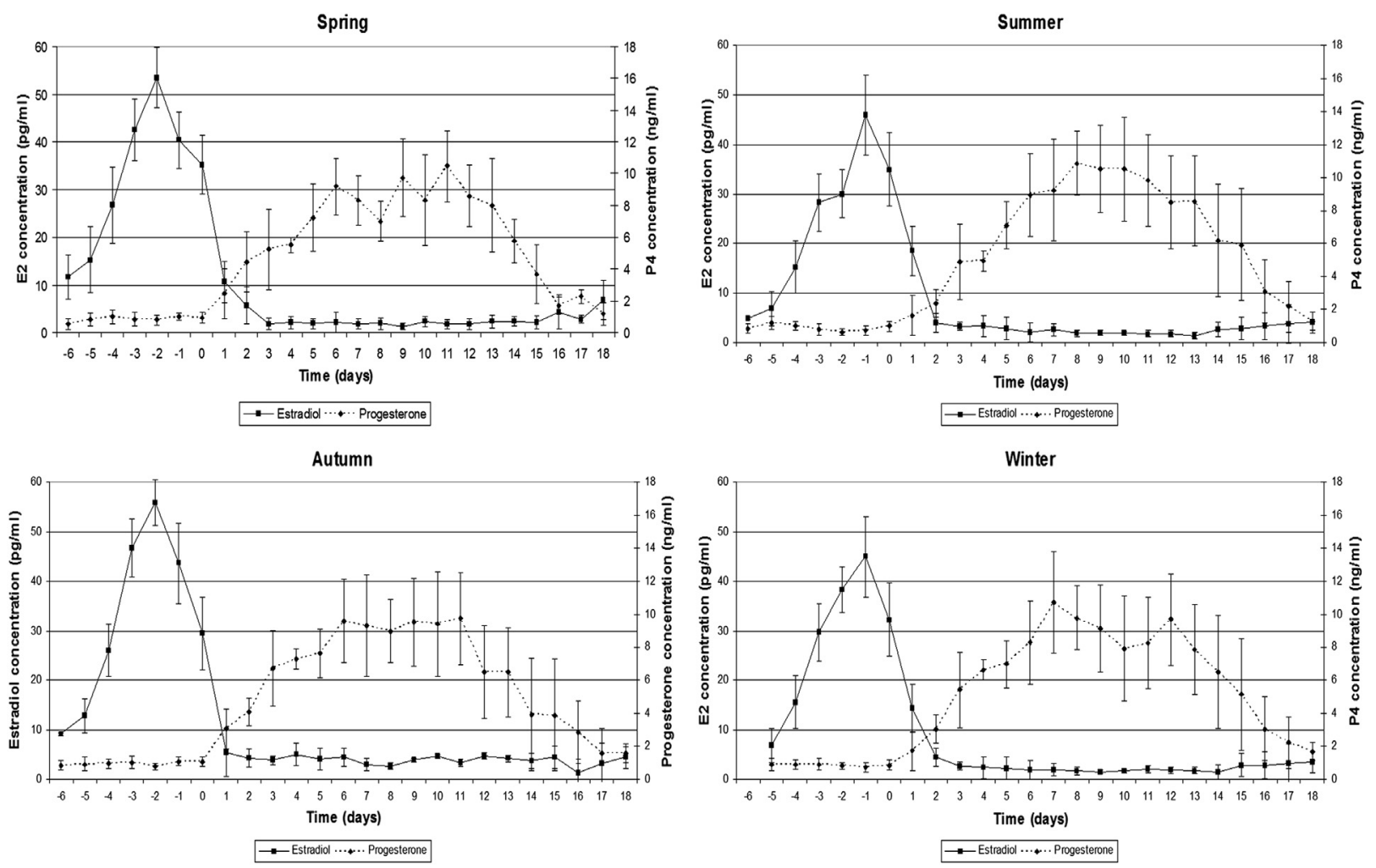

Fig. 1. Mean circulating patterns of estradiol-17 $\beta$ (E2) and progesterone (P4) along the estrous cycle of different seasons in Martina Franca jenny.

comparable with data reported in the jenny by Blanchard, et al. [22] (5.9 \pm 2.1 and $17.4 \pm 2.6$ days), but a different effect of the season was detected. Our data showed an increased estrous duration in summer compared with autumn and winter, and a reduced diestrous in summer compared with the other seasons. Blanchard, et al. [22] reported a variable but similar estrous length, and a significant reduction in diestrous length between October and March. These differences could be because of a different environmental conditions in which these studies were performed. The estrous length resulted comparable with the value reported in the mare $[17,18]$. However, the longer heat observed in summer in MF jennies was in contrast with the data reported in the mare, in which the estrus was shorter in summer than in autumn, as the result of an increased frequency of LH secretion during summer [26].

The behavioral signs of estrus in the jenny are very obvious. Clapping represents a typical estrous sign in the jenny and in the zebra [17], but it is not reported in the mare. This sign, together with winking and urination, is very easy to be observed at teasing with the jackass. Clapping could be observed, although less strongly, in the same jennies, also in the absence of the jackass, but when they are kept in group. Therefore, when this sign is observed, probably the jennies are in estrus.

Although criteria for impending ovulation estimation seems similar to that reported for the mare by Carnevale, et al. [27], the follicle size recorded in the last 6 hours before ovulation in the MF jennies in spring $(45 \pm 0.23 \mathrm{~mm})$ and summer $(44.2 \pm 0.32 \mathrm{~mm})$ were similar to that reported in the horse at the same time of the year (MayJune) [28].

The pattern of E2 and P4 plasma concentrations during the estrous cycle was similar to that reported for the mare. Estrogens increased during estrus, as the consequence of an increased growth and activity of the granulosa cells within the dominant follicle. The sharp reduction in the circulating estrogens from 2 days before ovulation, and a following slower decrease between Days 1 and 4 is a well-known pattern in the horse $[29,30]$ and could be involved in the concomitant increase of the circulating LH. The effect of season on ovarian steroids plasma concentrations seems to be negligible, because E2 peak was slightly delayed (Day 1) only in summer.

The pattern of P4 plasma concentrations during the estrous cycle was comparable with what reported in the mare [31], and the basal estrous level of $\mathrm{P} 4(<1 \mathrm{ng} / \mathrm{mL})$ detected in the jenny was similar to that classically reported in the mare [26,32].

\subsection{Conclusions}

The jennies monitored in this study showed ovulatory heats in all seasons of the year, with estrous cycles' length significantly longer in summer compared with autumn and winter. On the other hand, diestrus was significantly reduced during summer compared with the other seasons. The estrus was characterized by an increase of the circulating E2 with slight difference between seasons, with a peak 2 days (spring and autumn) or 1 day (summer and 
winter) before ovulation. Diestrus was characterized by an increase in plasmatic P4, that reaches a plateau at Day 6 to 11 (spring, summer, and autumn) or Day 12 (winter), then decreased until values below $2 \mathrm{ng} / \mathrm{mL}$ at the beginning of the following estrus. The heat behavior could be easily evocable by jackass teasing and was characterized by unequivocal signs, different to those reported in the mare. The jennies seemed to ovulate follicles with similar size and characteristics in the four seasons of the year, thus the criteria used for ovulation monitoring could be the same during the whole year.

\section{Acknowledgments}

This research was funded by FIRST (2004), University of Teramo. The Authors are grateful to Senator Dario Stefano, Dr. Filippo Nico, and Dr. Silvio Schito, from the Assessorato alle Politiche Agricole della Regione Puglia (Italy), and Dr. Pasquale Solazzo, Head of the Istituto Incremento Ippico di Foggia (Italy) for their support.

\section{References}

[1] Vidament M, Vincent P, Martin FX, Magistrini M, Blesbois E. Differences in ability of jennies and mares to conceive with cooled and frozen semen containing glycerol or not. Anim Reprod Sci 2009;112: 22-35.

[2] Gastal MO, Henry M, Beker AR, Gastal EL, Gonçalves A. Sexual behavior of donkey jacks: influence of ejaculatory frequency and season. Theriogenology 1996;46:593-603.

[3] Gastal MO, Henry M, Beker AR, Gastal EL. Effect of ejaculation frequency and season on donkey jack semen. Theriogenology 1997;47: 627-38.

[4] Pugh DG. Donkey reproduction. Proc Annu Convention AAEP 2002; 48:113-4.

[5] Miró J, Lobo V, Quintero-Moreno A, Medrano A, Peña A, Rigau T. Sperm motility patterns and metabolism in Catalonian donkey semen. Theriogenology 2005;63:1706-16.

[6] Contri A, De Amicis I, Veronesi MC, Faustini M, Robbe D, Carluccio A. Efficiency of different extenders on cooled semen collected during long and short day length seasons in Martina Franca donkey. Anim Reprod Sci 2010;120:136-41.

[7] Quartuccio M, Marino G, Zanghì A, Garufi G, Cristarella S. Testicular volume and daily sperm output in Ragusano donkeys. J Equine Vet Sci 2011;31:143-6.

[8] Carluccio A, Panzani S, Tosi U, Faustini M, De Amicis I, Veronesi MC. Efficacy of hCG and GnRH for inducing ovulation in the jenny. Theriogenology 2007;68:914-9.

[9] Carluccio A, Panzani S, Contri A, Tosi U, De Amicis I, Veronesi MC Luteal function in jennies following PGF(2alpha) treatment 3 days after ovulation. Theriogenology 2008;70:121-5.

[10] Contri A, Tosi U, De Amicis I, Veronesi MC, Panzani S, Carluccio A. Ultrasonographic evaluation of sexual glands before and after ejaculation in the jackass. Vet Res Commun 2008;32:S135-7.

[11] Veronesi MC, Panzani S, Govoni N, Kindahl H, Galeati G, Robbe D, et al. Peripartal plasma concentrations of 15-ketodihydro-PGF2 $\alpha$, cortisol, progesterone and estradiol-17 $\beta$ in Martina Franca jennies. Theriogenology 2011a;75:752-9.
[12] Veronesi MC, De Amicis I, Panzani S, Kindahl H, Govoni N, Probo M, et al. PGF $(2 \alpha)$, LH, testosterone, oestrone sulphate, and cortisol plasma concentrations around sexual stimulation in jackass. Theriogenology 2011b;75:1489-98.

[13] Camillo F, Panzani D, Scollo C, Rota A, Crisci A, Vannozzi I, et al. Embryo recovery rate and recipients' pregnancy rate after nonsurgical embryo transfer in donkeys. Theriogenology 2010;73:959-65.

[14] Panzani D, Rota A, Crisci A, Kindahl H, Govoni N, Camillo F. Embryo quality and transcervical technique are not the limiting factors in donkey embryo transfer outcome. Theriogenology 2012;77:563-9.

[15] Henry M, Figueiredo AEF, Palhares MS, Coryn M. Clinical and endocrine aspects of oestrous cycle in donkeys (Equus asinus). J Reprod Fert 1987;35:297-303.

[16] Carluccio A, Panzani S, Contri A, Bronzo V, Robbe D, Veronesi MC. Influence of season on testicular morphometry and semen characteristics in Martina Franca jackasses. Theriogenology 2013;79: $502-7$.

[17] Godelieve M, Vandeplassche GM, Wesson JA, Ginther OJ. Behavioral, follicular and gonadotropin changes during the estrous cycle in donkeys. Theriogenology 1981;16:239-49.

[18] Ginther OJ, Scraba ST, Bergfelt DR. Reproductive seasonality of the jenny. Theriogenology 1987;27:587-92.

[19] Meira C, Ferriera JCP, Papa FO, Tornero MTT, Bicudo SD. Study of the estrous cycle in donkeys (Equus asinus) using ultrasonography and plasma progesterone concentrations. Biol Reprod Mono 1995;1: 403-10.

[20] Pierson RA, Ginther OJ. Follicular population dynamics during the oestrous cycle of the mare. Anim Reprod Sci 1987;14:219-31.

[21] Bono G, Cairoli F, Tamanini C, Abrate L. Progesterone, estrogen, LH, FSH and PRL concentrations in plasma during the estrous cycle in goat. Reprod Nutr Dev 1983;23:217-22.

[22] Blanchard TL, Taylor TS, Love CL. Estrous cycle characteristics and response to estrus synchronization in mammoth asses (Equus asinus americanus). Theriogenology 1999;52:827-34.

[23] Hart PJ, Squires EL, Imel KJ, Nett TM. Seasonal variation in hypothalamic content of gonadotropin-releasing hormone $(\mathrm{GnRH})$, pituitary receptors for GnRH, and pituitary content of luteinizing hormone and follicle-stimulating hormone in the mare. Biol Reprod 1984;30:1055-62.

[24] Grubaugh W, Sharp DC, Berrglund LA, McDowel KJ, Kilmer DM, Peck LS, et al. Effect of pinealectomy in pony mares. J Reprod Fertil Suppl 1982;32:293-5.

[25] Kilmer DM, Sharp DC, Berglund LA, Grubaugh W, McDowel KJ, Peck LS. Melatonin rhythms in Pony mares and foals. J Reprod Fertil Suppl 1982;32:303-7.

[26] Ginther OJ. Reproductive biology of the mare (Basic and applied aspects). In: Ginther OJ, editor. 2nd edn. WI, USA: Equiservices Publication; 1992.

[27] Carnevale EM, McKinnon AO, Squires EL, Voss JL. Ultrasonographic characteristics of the preovulatory follicle preceding and during ovulation in the mare. J Equine Vet Sci 1988;8:428-31.

[28] Ginther OJ, Gastal EL, Gastal MO, Beg MA. Dynamics of the preovulatory follicle and periovulatory hormones: what's new? J Equine Vet Sci 2008;28:454-60.

[29] Ginther OJ, Gastal EL, Gastal MO, Beg MA. Regulation of circulating gonadotropins by the negative effects of ovarian hormones in mares. Biol Reprod 2005;73:315-23.

[30] Jacob JC, Gastal EL, Gastal MO, Carvalho GR, Beg MA, Ginther OJ. Temporal relationships and repeatability of follicle diameters and hormone concentrations within individuals in mares. Reprod Dom Anim 2009;44:92-9.

[31] Aurich C. Reproductive cycles of horses. Anim Reprod Sci 2011;124: $220-8$.

[32] Loy RG, Swan SM. Effects of exogenous progestogens on reproductive phenomena in mares. J Anim Sci 1966;25:821-6. 